\title{
Promoter Organization and Activity of Human Monoamine Oxidase (MAO) A and B Genes
}

\author{
Qin-shi Zhu, Joseph Grimsby, Kevin Chen, and Jean C. Shih \\ Department of Molecular Pharmacology and Toxicology, School of Pharmacy, University of Southern California, Los \\ Angeles, California 90033
}

\begin{abstract}
Monoamine oxidase A and B (MAO A and B) play important roles in the metabolism of biogenic and dietary amines and are encoded by two genes derived from a common ancestral gene. The promoter regions for human MAO $A$ and $B$ genes have been characterized using a series of $5^{\prime}$ flanking sequences linked to a human growth hormone reporter gene. When these constructs were transfected into NIH3T3, SHSY$5 Y$, and COS7 cells, the maximal promoter activity for MAO A was found in a 0.14 kilobase (kb) Pvull/Drall fragment (A0.14) and in a $0.15 \mathrm{~kb}$ Pstl/Nael fragment (BO.15) for MAO $B$. Both fragments are GC-rich, contain potential Sp1 binding sites, and are in the region where the MAO A and $B 5^{\prime}$ flanking sequences share the highest identity (approximately $60 \%$ ). However, the organization of the transcription elements is distinctly different between these two promoters. Fragment A0.14 consists of three Sp1 elements, all in reversed orientations, and lacks a TATA box. Two of the Sp1 sites are located within the downstream 90 base pair (bp) direct repeat, and the third is located at the 3 ' end of the upstream 90 bp direct repeat. Fragment B0.15 contains an Sp1-CACCCSp1-TATA structure; deletion of any of these elements reduced promoter activity. Additional Sp1 sites, CACCC elements, CCAAT boxes, and direct repeats (four 30 bp direct repeats in MAO A and two 29 bp direct repeats in MAO B) are found in farther-upstream sequences of both genes (1.27 $\mathrm{kb}$ for MAO A and mostly in $0.2 \mathrm{~kb}$ for MAO B). Inclusion of these sequences decreased promoter activity. The different promoter organization of MAO A and B genes provides the basis for their different tissue- and cell-specific expression.
\end{abstract}

Monoamine oxidase A and B (MAO A and MAO B, respectively; deaminating, flavin-containing amine: oxygen oxidoreductase, EC 1.4.3.4) catalyze the oxidative deamination of both endogenous amines, including neuroactive and vasoactive amines (von Korff, 1979), and exogenous amines, like dietary amines and the parkinsonism-producing neurotoxin 1-methyl-4-phenyl-1,2,3,6-tetrahydropyridine (Chiba et al., 1984; Fritz et al., 1985). MAO A preferentially oxidizes the biogenic amines such as 5-HT and is irreversibly inactivated by low concentrations

\footnotetext{
Received Oct. 16, 1991; revised June 8, 1992; accepted June 11, 1992.

This work was supported by Grant R01 MH37020, R37 MH39085 (Merit Award), and Research Scientist Award K05 MH00796, from the National Institute of Mental Health. Support from the Boyd and Elsie Welin Professorship is also appreciated.

Correspondence should be addressed to Jean C. Shih, Ph.D., Department of Molecular Pharmacology and Toxicology, School of Pharmacy, University of Southern California, 1985 Zonal Avenue, Los Angeles, CA 90033.

Copyright (C) 1992 Society for Neuroscience 0270-6474/92/124437-10\$05.00/0
}

of acetylenic inhibitor clorgyline (Johnston, 1968). MAO B preferentially oxidizes phenylethylamine and benzylamine and is inactivated by the irreversible inhibitors pargyline and deprenyl (Knoll and Magyar, 1972). Dopamine, tyramine, and tryptamine are common substrates for both forms of MAO. Both A and $B$ are mitochondrial outer membrane enzymes (Greenawalt and Schnaitman, 1970).

The cloning of the cDNAs for MAO A and B unambiguously demonstrates that these two proteins are coded by separate genes (Bach et al., 1988; Hsu et al., 1988; Ito et al., 1988; Kuwahara et al., 1990). The deduced amino acid sequences of the human liver MAO A and B share $70 \%$ identity. Moreover, the genes for MAO A and B have strikingly similar genomic structures: both consist of 15 exons and exhibit identical exon-intron organizations, suggesting that MAO A and MAO B are derived from duplication of a common ancestral gene (Grimsby et al., 1991). The MAO A and B genes reside closely between bands Xp11.23 to Xp22.1 of the X chromosome (Ozelius et al., 1988; Lan et al., 1989) and are deleted in some Norrie disease patients (Lan et al., 1989; Sims ct al., 1989; for review, see Shih, 1991).

While both MAO A and MAO B can be detected in most human tissues examined, they are however distributed differently in certain cells and tissues. For example, human placenta expresses predominantly MAO A (Egashira and Yamanaka, 1981; Hsu et al., 1988; Grimsby et al., 1990); human platelets and lymphocytes contain only MAO B (Bond and Cundall, 1977; Donnelly and Murphy, 1977). The neural distributions of MAO $A$ and $B$ enzyme activities are different. In human brain, high levels of MAO B are expressed in astrocytes and serotonergic neurons, while high levels of MAO A are expressed in catecholaminergic neurons (Fowler et al., 1987; Thorpe et al., 1987). A similar distribution has been observed in rats (Levitt et al., 1982) and in monkeys (Westlund et al., 1985). Furthermore, MAO A and $B$ expression is also different during development. MAO A activity appears before MAO B activity in fetal brain (Lewinsohn et al., 1980), whereas MAO B activity is higher than MAO A in adult human brain (Garrick and Murphy, 1982). The results of Northern analysis of MAO A and B transcripts are consistent with the distribution of their catalytic activities (Grimsby et al., 1990). In order to understand the mechanisms controlling the expression of these two forms of MAO, it is essential to characterize the promoter regions of their genes.

Transcription factors activate or depress gene transcription by interacting with the polymerase complex directly, or with other transcription factors. Most genes transcribed by DNA polymerase II contain a special sequence that aids initiation and specifies the locations where transcription initiation starts, such as TATA box (Breathnach and Chambon, 1981), Initiator (Inr) 
(Smale et al., 1990), or Housekeeping Initiator Protein 1 (HIP1) (Means and Farnham, 1990). The other commonly present element is the CCAAT box (Breathnach and Chambon, 1981), which binds a series of transcription factors (Santoro et al., 1988). Some genes, such as housekeeping genes, generally do not contain TATA or CCAAT boxes. Instead, their promoter sequences are GC-rich and contain binding sites for another type of transcription factor called $\mathrm{Sp} 1$ (core binding sequence GGGCGG; Dynan et al., 1986). Many other cis-elements have been identified. For example, CACCC is a binding site for a number of proteins (Gumucio et al., 1988; Schule et al., 1988) that generally activate transcription by interaction with other transcription factors. Some binding sites for protein factors are known to be responsive to external signals. For example, the AP-1 site (TGACTCA), which binds protein Jun and Fos, is responsive to growth factors and other cellular constituents (Curran and Franza, 1988). The sequence TGACGTCA, called cAMP response element (Montminy et al., 1986), can activate transcription when cAMP level is increased.

In this report, we have identified the DNA sequences responsible for transcription activation of MAO A and B genes. Our results show that the immediate $5^{\prime}$ flanking sequences of both MAO A and MAO B gene contain cis-elements needed for active transcription, but the organizations of these elements are different.

\section{Materials and Methods}

$D N A$ cloning. A 14 kilobase $(\mathrm{kb})$ MAO A genomic DNA ( $\lambda-35-\mathrm{A} 8 \mathrm{a})$ was isolated from an $\mathrm{X}$ chromosome-specific library cloned in phage $\lambda$-charon 35 (American Type Culture Collection) as previously reported (Grimsby et al., 1991). From the $14 \mathrm{~kb}$ clone, a $5 \mathrm{~kb}$ HindIII/SphI fragment that contains exon 1 and $4.6 \mathrm{~kb} 5$ ' flanking sequences was subcloned into pUC19. Exon 1 and $1.4 \mathrm{~kb} 5^{\prime}$ flanking sequences were determined by an Applied Biosystems model ABI 370a automated DNA sequencer and manually by the dideoxy chain-termination method (Sanger et al., 1977) and deposited in GenBank (accession no. M89636).

A $\lambda$-clone ( $\lambda$-35-Bla) with a $16 \mathrm{~kb}$ genomic DNA fragment containing MAO B exon 1 and $3.2 \mathrm{~kb} 5^{\prime}$ and $13.7 \mathrm{~kb} 3^{\prime}$ flanking sequences was isolated previously from the same genomic library mentioned above for MAO A clones (Grimsby et al., 1991). From this clone, a $5.3 \mathrm{~kb}$ Sau3AI (partial)/EcoRI fragment containing exon 1 and $3.2 \mathrm{~kb} 5^{\prime}$ flanking sequences was subcloned into pUC19. The sequences of exon 1 and $1.5 \mathrm{~kb} 5$ ' flanking region have been determined and deposited in GenBank (accession no. M89637).

Sequence comparison and repeat search were carried out with $\mathrm{Ge}$ netics Computer Group and IntelliGenetics-Molecular Biology Software System programs, respectively.

Primer extension. Primer extension for MAO A was performed according to Primer Extension System technical bulletin TB1 13, Promega Corp. ${ }^{32} \mathrm{P}$-labeled oligonucleotide (A59-29) complimentary to bases 5929 of the MAO A cDNA sequence (Bach et al., 1988) were annealed with $12 \mu \mathrm{g}$ total RNA samples from SHSY-5Y (human neuroblastoma) cells and HEL (human erythroleukemia) cells for $20 \mathrm{~min}$ at $58^{\circ} \mathrm{C}$ (SHSY$5 Y$ cells express both MAO A and B; HEL cells express only MAO A). Yeast tRNA was used as a control. Primer extension for MAO B was performed according to the method of Sambrook et al. (1989). ${ }^{32} \mathrm{P}$ labeled oligonucleotide (B30-1) complimentary to bases 30-1 of the MAO B cDNA sequence (Bach et al., 1988) was annealed to $60 \mu \mathrm{g}$ total RNA samples from SHSY -5Y cells for $12 \mathrm{hr}$ at $30^{\circ} \mathrm{C}$. Extension products were analyzed on a sequencing gel. A dideoxy sequencing reaction was used for detcrmining the size of extension products.

Determination of promoter activity. In order to identify the DNA sequences important for initiation of transcription, on the basis of sequence analyses and primer extension, various DNA fragments containing potential transcription factor binding sites were isolated from the presumed promoter regions of MAO A and MAO B genes [the 5 $\mathrm{kb}$ HindIII/SphI clone of MAO A and the $5.3 \mathrm{~kb}$ Sau3AI (partial)/ EcoRI MAO B clone, respectively]. After modifying their restriction ends by first cloning into pUC19, these fragments were then cloned into promoterless transient expression vector pOGH, which contains the human growth hormone as the reporter gene (Nichols Institute Diagnostics) (Selden et al., 1986). Care has been taken not to introduce ATG translation start codon into pOGH. This was achieved by using a DraII site in MAO A gene [ 8 base pair (bp) $3^{\prime}$ of the cDNA start site; see Fig. 2] and a Sau3AI site in the MAO B gene (19 bp 3' of the cDNA start site; see Fig. 3) as the $3^{\prime}$ limit of these fragments. These constructs were then transfected into NIH3T3 cells (mouse fibroblasts), COS7 cells (virally transformed African green monkey kidney cells), and SHSY-5Y cells (a human neuroblastoma cell line) using the low $\mathrm{pH}$ calcium phosphate coprecipitation method (Chen and Okayama, 1987). The human growth hormone produced was excreted into medium and measured by a radioimmunoassay using a kit from Nichols Diagnostics. In this assay, two monoclonal antibodies were used, each specific for a different epitope on hGH molecule. Essentially all hGH molecules are fixed on biotin-coated beads through the avidin-coupled antibody. The other antibody is radiolabeled for detection. It can be fixed on the beads only through the hGH molecules associated with the beads. After the free radioactive antibody molecules have been washed away, the amount of the radioactive antibody remaining attached to the beads and measured as counts per minute will be directly proportional to the number of hGH molecules in the medium.

All measurements were made with duplicated dishes to minimize dish-to-dish variation. Each construct was measured at least twice, and the average was reported. The differences in duplicate measurements were less than $10 \%$. To monitor the transfection efficiency, plasmid pXGH5 (in which mouse metallothionein promoter instead of human MAO promoter fragments is linked to the human growth hormone gene) was transfected under the same conditions and the growth hormone production was determined. Chloramphenicol acetyltransferase (CAT) plasmid was used as an internal control in cotransfection assays to test if transfection efficiency varies with the length of DNA inserts. We also examined the effect of impurities in construct preparations on transfection efficiency. This was done by comparing promoter activity of the same constructs prepared with different methods, one with two rounds of $\mathrm{CsCl}$ gradient centrifugation and the other with a column (from 5 Prime $\rightarrow 3$ Prime, Inc.) that specifically removes genomic DNA. These tests showed that transfection efficiencies were similar for the constructs we used.

$M A O$ activity assay. MAO activity was assayed as previously described (Chen et al., 1984). The $1 \mathrm{ml}$ assay mixture contained $50 \mathrm{~mm}$ sodium phosphate buffer ( $\mathrm{pH} 7.4$ ), $100 \mu \mathrm{M}{ }^{14} \mathrm{C}$-serotonin (for MAO A) or $10 \mu \mathrm{M}{ }^{14} \mathrm{C}$-phenylethylamine (for MAO B), and cell homogenate of $\mathrm{NIH} 3 \mathrm{~T} 3, \mathrm{COS} 7$, and SHSY $-5 \mathrm{Y}$ cells. After $20 \mathrm{~min}$ incubation at $37^{\circ} \mathrm{C}$, $0.1 \mathrm{ml}$ of $6 \mathrm{~N} \mathrm{HCl}$ was added to terminate the reaction. The reaction products were extracted with $6 \mathrm{ml}$ of either ethyl acetate/benzene $(1: 1$, $\mathrm{v} / \mathrm{v}$ ) or toluene when serotonin or phenylethylamine was used as the substrate, respectively. The tubes were centrifuged at $2000 \mathrm{rpm}$ for 10 $\mathrm{min}$ to separate the two phases. Four milliliters of the organic layer was withdrawn and mixed with $5 \mathrm{ml}$ of scintillation fluid. The radioactivity of the reaction product was determined by liquid scintillation spectroscopy.

\section{Results}

Examination of the sequences in the presumed promoter regions of MAO A and B revealed that the regions immediately $5^{\prime}$ of the cDNA start sites of these two genes are both GC-rich. The first 200 bp 5' flanking sequences in the MAO A and B genes contain $68 \%$ and $82 \%$ GC residues, respectively. Furthermore, these two regions show $61 \%$ sequencc identity (Fig. 1), suggesting that the MAO A and B promoters may be derived from a common ancestral promoter. The sequence similarity between MAO $\mathrm{A}$ and $\mathrm{B}$ promoters could be extended at least another $100 \mathrm{bp}$ farther upstream (Fig. 1). However, none of the potential transcription factor binding sequences are conserved at their corresponding positions (Fig. 1), suggesting that these two promoters have functionally diverged during evolution. The arrangement of cis-elements (represented by symbols) and direct repeats (arrows) possibly involved in transcription regulation are shown in Figures 2 and 3 for MAO A and B, respectively. The potential transcription factor binding sites are numbered sequentially from $3^{\prime}$ to $5^{\prime}$. The sequence and the location of 


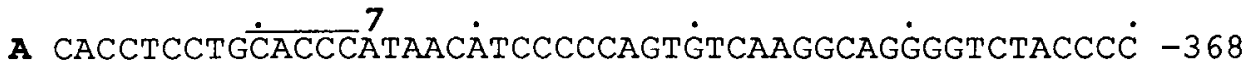
|| ||| | || | | | ||| | | || || | | | | |

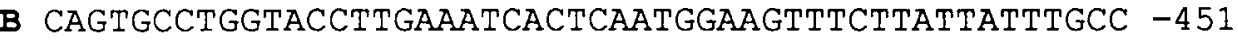

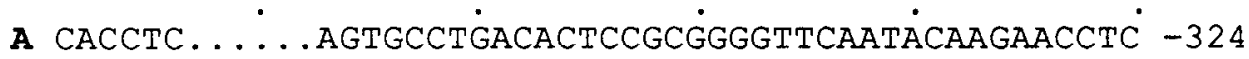

B CTACACCCAAGGAGTAATTGGGGCCCTGAAGGAAGACACCCCAATTTGCC $1615 \quad 1513$

A CTGCACCCÁGTAATCCTTTCCAGCTGCCGÁCACAAGGACÁTTCTAAACC $\dot{\bar{T}}-274$

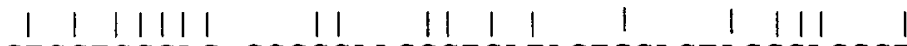

B GTCCTCCCAG. CCGCCAAGCCTGATAGTGCACTAGGGAGGCTGATGGGAA -352

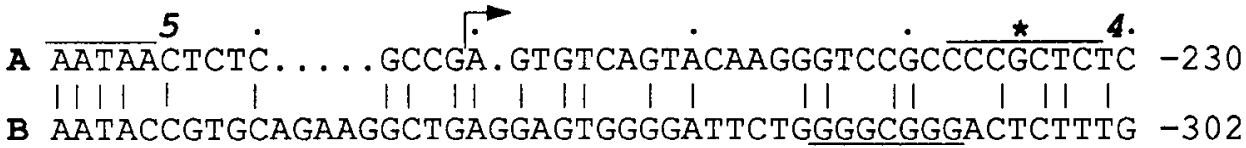
12

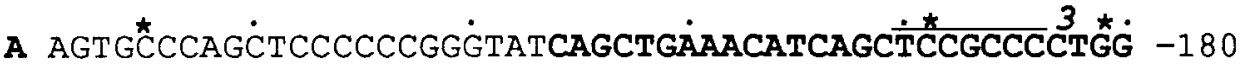

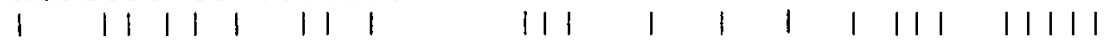

B AAGTCCTAGGTGACCTCTCCGCCCAG. GCACCCGCCCTCCCCGGGCCTGG -253

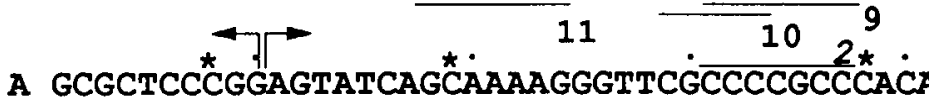

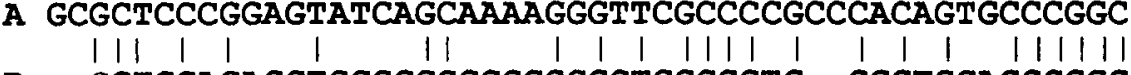

B .. GCTGCAGAGCTGCGGGCGGGGGCGGTGGCCCTG. . CGCTGCACCCGGC -207

A TCCCCCCGGGTATCAAAAGAAGGATCGGCTCCGCCCCCGGGCTCCCCGGG

1||||$|1||1||1| 1|1| 1|1| 1 \mid$

B CTGCCTGCGCGTAGGCGGGCGGGCGGGGCTGCGCGTCC.GGGT. CCCGGG -158

A GGAGTTGATAGAAGGTCCTTCCCACCCTTTGCCGTCCCCACTCCTGTGC -30

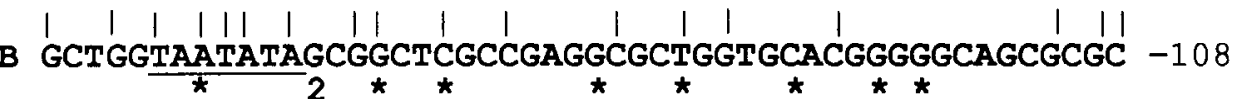

A CTACGACCCAGGAGCGTGTCAGCCAAAGCATG +3

B AGCAGGCCGGCGGGCAGGCGGGCGGGCTGG्GT -76

these cis-elements are summarized in Table 1. Parts of these cis-elements (sites 1-7 of MAO A and sites 1-16 of MAO B) are also shown in Figure 1 (the MAO A sites are overlined, and the MAO B sites are underlined).

No TATA box or CCAAT box was found in the genomic sequences near the MAO A cDNA start site (-73, marked by an open arrow in Fig. 1, the A of the ATG codon being taken as position +1 ; Bach et al., 1988). Instead, two $90 \mathrm{bp}$ direct repeats, with $83 \%$ sequence homology, are located immediately $5^{\prime}$ of the cDNA start site (from -80 to -169 and from -170 to -259 , respectively; Fig. 1, marked by solid arrows; Fig. 2, marked by two open arrows). Each repeat contains two potential Spl binding sites: sites 1 and 2 in the downstream repeat and sites 3 and 4 in the upstream repeat (Figs. 1, 2). Note that all these four $\mathrm{Spl}$ sites are in reversed form of the core consensus sequence GGGCGG (Dynan et al., 1986). Ten bp $5^{\prime}$ of these two 90 bp repeats is a TAATAA sequence (at -269 , Figs. 1, 2, site 5). Two CCAAT boxes (Fig. 2, Table 1, sites 8, 11 ) and four CACCC elements (sites 6, 7, 9, 10) were found within $300 \mathrm{bp}$ upstream of this TAATAA sequence.

Additional potential transcription factor binding sites for the
Figure 1. Sequence comparison between core region of MAO A and $\mathrm{B}$ promoters. Genomic sequence -427 to +3 of MAO A gene and -500 to -76 of MAO B gene are aligned to show sequence homology and to compare locations of the cis-elements, the cDNA start site, and the transcription initiation sites in each gene. The letters $A$ and $B$ on the left side indicate MAO A and $B$ sequence, respectively. Nucleotide numbers are marked on the right side. The A of the translation start codon ATG of both genes is defined as +1 , and only the ATG of MAO A gene is shown (in boldface). The sequences of A0.14 and B0.15 fragments are shown in boldface. The cis-elements in these regions are overlined (for MAO A) or underlined (for $\mathrm{MAO} \mathrm{B}$ ) and sequentially numbered from $3^{\prime}$ to $5^{\prime}$. The site numbers for MAO A are italic, to distinguish them from the ones for MAO $B$ gene. The two $90 \mathrm{bp}$ direct repeats of MAO A gene are marked by solid arrows. The cDNA start site is indicated by an open arrow. Transcription initiation sites as determined by primer extension experiments are marked with asterisks $(*)$.
MAO A gene have been found in the farther-upstream sequences (Fig. 2, Table 1), including three possible $\mathrm{Sp} 1$ binding sites (sites $14,17,18$ ), one CACCC element (site 13), and two CCAAT boxes (sites 15, 16). A cAMP response element-like sequence, TGACCTCA (consensus sequence TGACGTCA; Montminy et al., 1986) was found at -618 (site 12, Fig. 2). In addition, four direct repeats, each $30 \mathrm{bp}$ long and with $100 \%$ homology, are located in a head-to-tail fashion about $1.1 \mathrm{~kb} 5^{\prime}$ of the ATG initiation codon (marked by four solid arrows in Fig. 2). Immediately $3^{\prime}$ to these four direct repeats are the sequences of the first $\left(5^{\prime}\right.$ end) $12 \mathrm{bp}$ of each $30 \mathrm{bp}$ repeat (indicated with a short arrow connected to the four arrows). It appears that the MAO A promoter contains cis-elements distributed over a long stretch (about $1.4 \mathrm{~kb}$ ) of DNA.

The MAO B promoter region is quite different from MAO A. A potential TATA box (TAATATA; Figs. 1, 3, sitc 2) has been found at $146 \mathrm{bp} 5^{\prime}$ of the MAO B ATG codon (-146; the $A$ of the ATG initiation codon in MAO B is defined as +1$)$ and 68 bp $5^{\prime}$ of the MAO B cDNA start site ( -78 ; Bach et al., 1988; marked by an open arrow in Fig. 1). At 27 bp upstream of this TATA box (start from -179) are three overlapping potential 


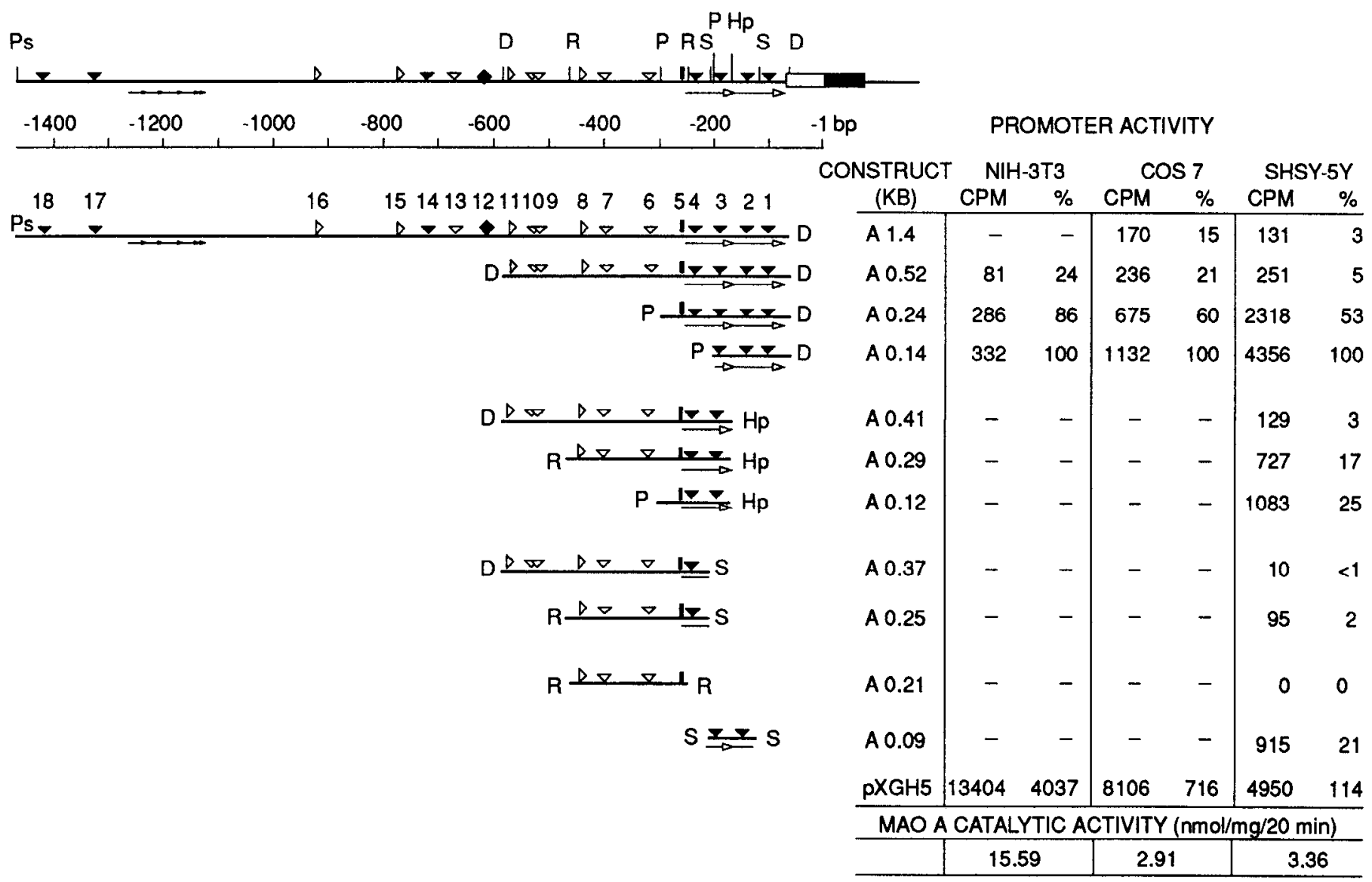

Figure 2. Restriction map of the MAO A promoter region and promoter activity measurements. At the top is the restriction enzyme map, where only the sites of the restriction enzymes used for subcloning for promoter activity measurement are marked. The open box on the top line represents untranslated region, and the solid box represents the coding sequence of MAO exon 1 . The potential transcription factor binding sites are numbered

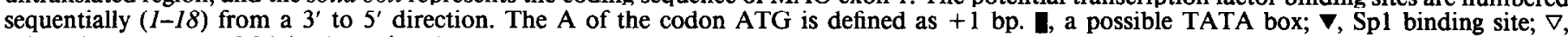
CACCC element; $\triangleright$, CCAAT box; $\uparrow$, cAMP response element-like sequence. The open arrows are the two 90 bp repeats, and the five short solid arrows are the four complete and one partial $30 \mathrm{bp}$ repeats. The pOGH constructs containing these DNA fragments are named according to the size of the inserts $(\mathrm{kb})$. A denotes DNA fragments of MAO A gene. The activity of the A0.14 constructs is taken as $100 \%$ for each cell line. The actual counts per minute given in this figure are the average of at least two measurements, with variation less than $10 \%$, and have been subtracted from background (pOGH without inserts), which was $300 \mathrm{cpm}$. pXGH5 (the third line from bottom) represents the plasmid containing mouse metallothionein promoter instead of the MAO promoter fragments, which was used to monitor the transfection efficiency. The bottom line shows MAO A enzymatic activity measured in each cell line. The restriction enzymes used were $D$, DralI; $H p$, HinpI; $P S$, PstI; $P$, PvuII; $R$, RsaI; and $S$, SmaI.

Sp1 sites: AGGCGGGCGGGCGGGG (sites 3, 4, 5 in Figs. 1, 3). At $30 \mathrm{bp}$ farther upstream $(-226)$ are two overlapping possible Spl binding sites: GGGCGGGGGCGGTG (sites 7, 8). Between these two Spl site clusters $(-210)$ is a CACCC motif (site 6). More potential transcription factor binding sites were found in a 200 bp segment $5^{\prime}$ to the possible sites mentioned above (Figs. 1, 3), including three more potential Spl binding sites (sites 9, 11, 12), three more CACCC sequences (sites 10, 14,16 ), and two CCAAT boxes (sites 13,15 ). At $3^{\prime}$ to the TATA box, immediately $5^{\prime}$ of the cDNA start site $(-82)$, is another possible Spl binding site (site 1). Only three known transcription factor binding sequences were found in the $1 \mathrm{~kb}$ sequences $5^{\prime}$ of -450 (Fig. 3, Table 1), including a single CACCC element (in the form of GGGTG) located at -709 (site 17), a cAMP response element-like sequence TGATGTCA (consensus TGACGTCA; see above) at -807 (site 18), and an AP-1 binding site TGACTCA at -1340 (site 19). Two 29 bp direct repeats, with $100 \%$ sequence homology, were located from -750 to -778 and from -779 to -807 , respectively (Fig. 3, marked with two arrows).
Primer extension experiments using total RNA from untransfected SHSY $-5 Y$ cells revealed multiple transcription initiation sites for the MAO A gene (Fig. 4, lane 1), as expected for a promoter with multiple Spl binding sites. All of these initiation sites are located within the two $90 \mathrm{bp}$ direct repeats, between Spl sites 1 and 4 (Fig. 1, marked with asterisks). Same extension bands were obtained with total RNA from HEL (human erythroleukemia) cells (data not shown), but not with yeast tRNA, suggesting that these extension bands very likely represent real transcription initiation sites. The most upstream initiation site was at -235 , right on site 4,34 bp $3^{\prime}$ of the TAATAA sequence and 162 bp $5^{\prime}$ of the cDNA start site ( -73 , Fig. 1). The other initiation sites are located at $-225,-189,-181,-172,-161$, -142 , and -138 (Figs. 1, 4). The primer extension experiment for MAO B gene using the same SHSY-5Y total RNA also produced multiple extension bands (Fig. 4, lane 2). The longest, also the strongest, product (122 bp in Fig. 4) corresponds to the most upstream transcription initiation site at $-169,91$ bp upstream of MAO B cDNA start site (-78, Fig. 1). This cap site lay upstream of the TAATATA sequence (site 2, Fig. 1) and 


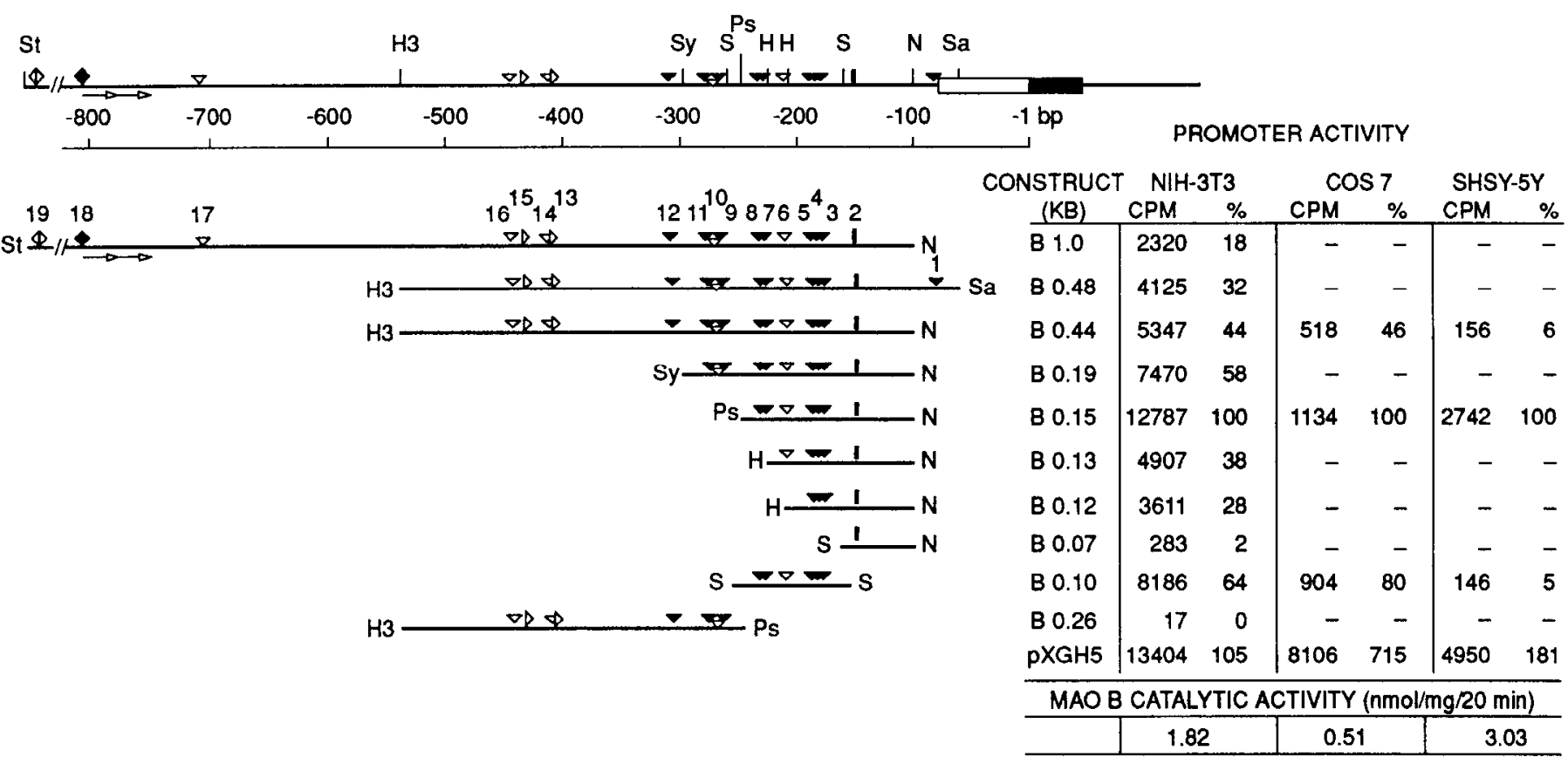

Figure 3. Restriction map of the MAO B promoter region and promoter activity measurements. The symbols used in this figure are the same as in Figure 2. The potential transcription factor binding sites are numbered sequentially $(1-19)$. $B$, DNA fragments from MAO B gene. The $t w o$ arrows represent the 29 bp repeats. pXGH5 (the third line from bottom) represents the plasmid containing mouse metallothionein promoter instead of MAO promoter fragments, which was used to monitor the transfection efficiency. The bottom line shows MAO B enzymatic activity measured in each cell line. The restriction enzymes used were $H$, HaeIII; $H 3$, HindIII; $N$, NaeI; $P s$, PstI; $S y$, StyI; Sa, Sau $3 A ; S$, SmaI; and $S t$, StuI.

downstream of the three overlapping $\mathrm{Sp} 1$ sites 3,4 , and 5 , suggesting TATA-independent initiation. The other bands correspond initiation sites at $-150,-142,-139,-132,-128$, $-123,-119$, and -117 (Figs. 1, 4). All these initiation sites, except the one at -150 , are downstream of the TAATATA sequence. The initiation site at -123 is 23 bp $3^{\prime}$ of the TAATATA sequence, suggesting also TATA-dependent transcription (Fig. 1).

To identify DNA sequences contributing to the promoter activity of MAO A and B genes, based on the above sequence analyses and primer extension data, a number of DNA fragments from their $5^{\prime}$ flanking regions were inserted into the transient expression vector ( $\mathrm{pOGH}$ ) containing human growth hormone as the reporter gene. The constructs thus obtained were transfected into NIH3T3, SHSY-5Y, and COS7 cells. NIH3T3 and SHSY-5Y cells contain both MAO A and B enzymatic activities, but minimum MAO B activity could be detected in COS7 cells (Figs. 2, 3). After transfection, the human growth hormone transiently expressed by these cells was determined by a radioimmunoassay, and the amount measured as counts per minute (cpm; see Materials and Methods) was used to estimate promoter activities of the inserted DNA fragments.

The highest MAO A promoter activity was observed with the A0.14 kb PvuII/DraII fragment in SHSY-5Y cells (Fig. 2, column 3). Since the highest MAO A promoter activity by pOGH constructs was observed in SHSY-5Y cells, the most detailed study on MAO A promoter was performed with this cell line. The A0.14 fragment contained the entire 3'90 bp repeat and half of the $5^{\prime} 90 \mathrm{bp}$ repeat. The measured activity $(4356 \mathrm{cpm})$ was taken as $100 \%$ and was comparable with that of the control metallothionein promoter in the plasmid pXGH5 $(4950 \mathrm{cpm})$ in the same cells. The A0.24 kb PvuII/DraII fragment, containing additional $5^{\prime}$ sequences, including the other half of the
5'90 bp repeat and the TAATAA sequence at -269 (site 5), exhibited $53 \%$ promoter activity (compare constructs A0.14 and A0.24 in Fig. 2, column 3). This result suggests that these additional sequences, including the TAATAA sequence, downregulate the gene expression. Inclusion of farther-upstream sequences led to even lower activity. The A0.52 kb DraII/DraII fragment and the A1.4 kb PstI/DraII fragment showed only 5\% and $3 \%$ activity, respectively. The lower promoter activity exhibited by longer DNA inserts in this in vivo experiment is not due to lower transfection efficiency of these constructs. Cotransfection with CAT plasmid as an internal control showed that the transfection efficiency was independent of the length of the inserts (data not shown). Therefore, these results suggest that the upstream sequences contain downregulating elements.

Removal of the 3' 90 bp repeat substantially reduces MAO A promoter activity (see the three fragments with HinpI site as their $3^{\prime}$ end). For example, the activity of the A0.12 PvuII/ HinpI fragment, which contains only the $5^{\prime} 90$ bp repeat, showed half the activity $(1083 \mathrm{cpm}, 25 \%)$ of the A0.24 PvuII/DraII fragment $(2318 \mathrm{cpm}, 53 \%)$, which contains both 90 bp repeats. This result indicates that the 3' 90 bp repeat plays an important role in MAO A expression. Addition of upstream sequences to this 3 '-truncated A0.12 fragment also decreased promoter activity, suggesting again that the upstream sequences are downregulating. For example, inclusion of the RsaI/PvuII segment (see A0.29 RsaI/HinpI fragment) decreased activity to $17 \%$ (727 cpm). The A0.41 Drall/HinpI fragment had only $3 \%$ activity $(129 \mathrm{cpm})$.

Further removal of the $3^{\prime}$ half of the $5^{\prime} 90$ bp repeat to generate DNA fragments with only one $S p 1$ site (site 4) reduced promoter activity to minimum. The A0.25 RsaI/SmaI fragment had only $2 \%$ activity $(95 \mathrm{cpm}$; compare with $\mathrm{A} 0.29 \mathrm{RsaI} / \mathrm{HinpI}$ fragment, which had $17 \%$ activity). This low activity was reduced to almost 


\begin{tabular}{|c|c|c|c|c|c|}
\hline \multicolumn{3}{|c|}{ MAO A } & \multicolumn{3}{|c|}{ MAO B } \\
\hline Site & Sequence & $\begin{array}{l}\text { Location } \\
\text { (bp) }\end{array}$ & Site & Sequence & $\begin{array}{l}\text { Location } \\
\text { (bp) }\end{array}$ \\
\hline 1 & CTCCGCCC & -94 & 1 & GGGCGGG & -82 \\
\hline 2 & CCCGCCC & -142 & 2 & TAATATA & -146 \\
\hline 3 & CTCCGCCC & -184 & 3 & GGGCGGG & -181 \\
\hline 4 & TCCGCCC & -237 & 4 & GGGCGGG & -185 \\
\hline 5 & TAATAA & -269 & 5 & AGGCGGG & -189 \\
\hline 6 & CACCC & -316 & 6 & $\mathrm{CACCC}$ & -210 \\
\hline 7 & CACCC & -404 & 7 & GGGCGGTG & -226 \\
\hline 8 & CCAAT & -443 & 8 & GGGCGGG & -233 \\
\hline 9 & CACCC & -521 & 9 & CCCGCCC & -267 \\
\hline 10 & CACCC & -531 & 10 & CACCC & -270 \\
\hline 11 & CCAAT & -570 & 11 & CTCCGCCC & -278 \\
\hline 12 & TGACCTCA & -618 & 12 & GGGCGGG & -310 \\
\hline 13 & CACCC & -670 & 13 & CCAAT & -405 \\
\hline 14 & CCCGCCC & -729 & 14 & CACCC & -409 \\
\hline 15 & CCAAT & -777 & 15 & AATTGG & -430 \\
\hline 16 & CCAAT & -920 & 16 & CACCC & -442 \\
\hline 17 & CACCGCCC & -1325 & 17 & GGGTG & -709 \\
\hline \multirow[t]{2}{*}{18} & CCCGCCC & -1418 & 18 & TGATGTCA & -807 \\
\hline & & & 19 & TGACTCA & -1340 \\
\hline
\end{tabular}

These sites are numbered from $3^{\prime}$ to $5^{\prime}$ as in Figures 1-3. The locations of these sites are indicated by the distance to the $\mathrm{A}$ of the translation initiation codon ATG, which is defined as +1 . The minus sign indicates that they are upstream of the ATG.

zero by the upstream DraII/RsaI fragment (see A0.37 DraII/ Smal fragment, which had less than $1 \%$ activity).

When both 90 bp repeats were completely removed (see A0.21 RsaI/Rsal fragment), the activity dropped to background level (see also Discussion about this fragment).

These results clearly show that MAO A promoter activity resides in the two $90 \mathrm{bp}$ repeat region. Moreover, the promoter activity seems distributed over the entire $180 \mathrm{bp}$ region of these two 90 bp repeats. For instance, promoter activity could be detected in the 5' repeat (see the A0.12 PvuII/HinpI fragment, which contains the Sp1 sites 3 and 4 and had $25 \%$ activity), the middle part (see A0.09 SmaI/SmaI fragment, which contains Spl sites 2 and 3 and exhibited $21 \%$ activity), and the $3^{\prime}$ part (see A0.14 PvuII/Drall fragment, which contains Sp1 sites 1, 2 , and 3 and had the highest promoter activity). These results are in good agreement with the primer extension data, which showed multiple transcription initiation sites within these two 90 bp direct repeats.

Similar results were obtained in COS7 cells (Fig. 2, column 2) and in NIH3T3 cells (Fig. 2, column 1), in which the highest promoter activity was seen in $\mathrm{A} 0.14 \mathrm{~kb}$ fragment, followed by $\mathrm{A} 0.24, \mathrm{~A} 0.52$, and $\mathrm{A} 1.4 \mathrm{~kb}$ fragments. The promoter activity for these constructs in COS7 cells was lower $(1132 \mathrm{cpm}$ for A0.14 fragment) than in SHSY-5Y cells $(4356 \mathrm{cpm}$ for the same constructs). This result is in agreement with the fact that MAO A catalytic activity is lower in COS cells $(2.91 \mathrm{nmol} / \mathrm{mg} / 20 \mathrm{~min})$ than in SHSY-5Y cells $(3.36 \mathrm{nmol} / \mathrm{mg} / 20 \mathrm{~min}$; see Fig. 2, bottom line). Low MAO A promoter activity was observed for these fragments in NIH3T3 cells (Fig. 2, column 1; $332 \mathrm{cpm}$ for A0.14 fragment) even though high mouse MAO A catalytic activity $(15.59 \mathrm{nmol} / \mathrm{mg} / 20 \mathrm{~min})$ was seen in these cells. The low promoter activity of these fragments observed in $\operatorname{COS} 7$ cells

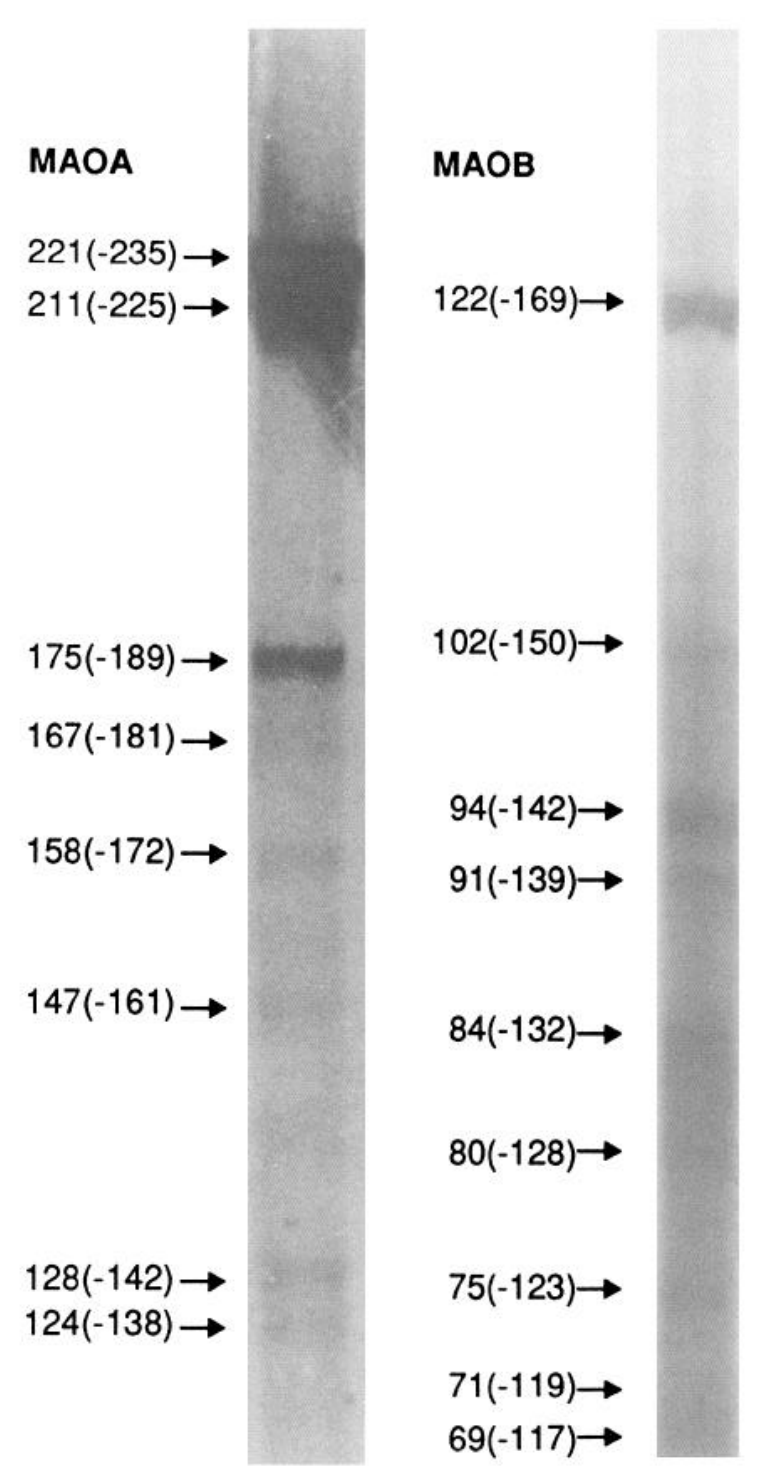

Figure 4. Primer extension analysis of human MAO A and B mRNA. The procedures used are described in Materials and Methods. Lane 1 , $12 \mu \mathrm{g}$ of SHSY-5Y total RNA analyzed with A59-29; lane 2, $60 \mu \mathrm{g}$ of SHSY $-5 Y$ total RNA analyzed with B30-1. The numbers denote the size (bp) of the extension products. The corresponding initiation sites (nucleotide sequences) are indicated in parentheses. These initiation sites are also marked in Figure 1 with asterisks $\left(^{*}\right)$.

and NIH3T3 cells was not due to low transfection efficiency of these two cell lines, because the control metallothionein promoter activity (in plasmid pXGH5) was high (8106 and 13,404 cpm in COS7 and NIH3T3 cells, respectively). It seems that the factors required for the control metallothionein promoter are different, and mouse (NIH3T3) cells may be lacking the transcription factors required for effective activation of human MAO A gene transcription.

For MAO B, the highest promoter activity was observed in NIH3T3 cells with the B0.15 kb Pstl/NaeI fragment (Fig. 3, column 1). For this reason, the most detailed study on MAO B promoter was carried out with NIH3T3 cells. The highest activity $(12,787 \mathrm{cpm})$ was taken as $100 \%$ and was comparable 
with that of the control metallothionein promoter in the plasmid pXGH5 (13,404 cpm). B0. 15 contains two Sp1 binding regions (sites 3-5 and 7, 8, respectively; see also Fig. 1), flanking a CACCC element, all upstream of a TAATATA sequence. Thus, the organization of the cis-elements in B0.15 is Sp1-CACCCSp1-TATA. Removal of the TAATATA sequence decreased the activity to $64 \%$ (see the $\mathrm{B} 0.1 \mathrm{~kb} \mathrm{Smal} / \mathrm{SmaI}$ fragment), indicating that this TATA box and/or its flanking sequences is essential for full transcription activity but TATA-independent transcription is more important. This result is in good agreement with the primer extension data, which showed multiple transcription initiation sites, with the major initiation site between the TATA box and the $3^{\prime} \mathrm{Sp} 1$ binding clusters (sites 3-5). Deletion from the $5^{\prime}$ end of the $\mathrm{B} 0.15 \mathrm{~kb}$ fragment, resulting in a stepwise loss of $5^{\prime} \mathrm{Spl}$ sites (sites 7, 8; see construct $\mathrm{B} 0.13$ ), the CACCC element (site 6; see construct B0.12), and the $3^{\prime} \mathrm{Sp} 1$ sites (sites 3-5; see construct B0.07), resulted in $38 \%, 28 \%$, and $2 \%$ of the promoter activity, respectively (Fig. 3, column 1). These results suggest that both $\mathrm{Spl}$ binding clusters and the CACCC motif in the B0.15 kb PstI/NaeI fragment have positive roles for MAO B expression. On the other hand, the sequences upstream or downstream from this structure seem to downregulate the MAO B gene expression. For example, inclusion of upstream sequences up to -295 (B0.19 construct) and -535 (B0.44 construct) resulted in $58 \%$ and $44 \%$ of the promoter activity, respectively. Inclusion of the downstream $\mathrm{Spl}$ site (site 1) further reduced the promoter activity to $32 \%$ (Fig. 3, column 1; compare the B0.44 kb HindIII/NaeI fragment and the B0.48 $\mathrm{kb}$ Hind III/Sau3AI fragment). The upstream sequences from the B0.15 fragment, tested with the B0.26 kb HindIII/PstI fragment, had no promoter activity.

Similar relative promoter activity of MAO B fragments was observed in COS7 cells (Fig. 3, column 2) and SHSY -5Y cells (Fig. 3, column 3). The highest promoter activity was produced by the B0.15 construct (taken as 100\%). Inclusion of the upstream sequences (Fig. 3, B0.44 construct) or removal of the TATA box (B0.10 construct) also decreased the promoter activity in both cell lines. Such modifications caused a more dramatic decrease in promoter activity in SHSY-5Y cells (Fig. 3, column $3 ; 6 \%$ and $5 \%$ for $\mathrm{B} 0.44$ and $\mathrm{B} 0.10$, respectively) than in COS7 cells (Fig. 3, column 2; 46\% and $80 \%$ for B0.44 and $\mathrm{B} 0.10$, respectively). The actual promoter activity observed with B0.15 fragment was lower in COS7 cells $(1134 \mathrm{cpm})$ than in NIH3T3 cells $(12,787 \mathrm{cpm})$. Again, this low MAO B promoter activity in $\operatorname{COS} 7$ cells was not due to low transcription efficiency, since the control metallothionein promoter had high activity in COS7 cells $(8106 \mathrm{cpm})$. In SHSY-5Y cells, the B0.15 fragment and the metallothionein promoter showed comparable activity (2742 and $4950 \mathrm{cpm}$, respectively). These results are also in agreement with the enzyme activity data, which show that SHSY$5 \mathrm{Y}$ cells express much more MAO B activity $(3.03 \mathrm{nmol} / \mathrm{mg} /$ $20 \mathrm{~min})$ than COS7 cells $(0.51 \mathrm{nmol} / \mathrm{mg} / 20 \mathrm{~min}$; see Fig. 3 , bottom line). In the human cell line we used (SHSY -5Y), there is also good correlation between promoter activities $(4356 \mathrm{cpm}$ for $\mathrm{A} 0.14$ and $2742 \mathrm{cpm}$ for B0.15) and catalytic activities (3.36 $\mathrm{nmol} / \mathrm{mg} / 20 \mathrm{~min}$ for MAO A and $3.03 \mathrm{nmol} / \mathrm{mg} / 20 \mathrm{~min}$ for MAO B). The unusually high MAO B promoter activity in NIH3T3 cells $(12,787 \mathrm{cpm})$ compared with moderate mouse M $\Lambda$ O B enzymatic activity $(1.82 \mathrm{nmol} / \mathrm{mg} / 20 \mathrm{~min})$ suggests that the mouse fibroblast cells contain sufficient activating factors or less inhibiting factors for human MAO B constructs. The poor correlation observed in mouse (NIH3T3) cells between mea- sured human MAO promoter activities $(332 \mathrm{cpm}$ for A0.14 and $12,787 \mathrm{cpm}$ for $\mathrm{B} 0.15$ ) and mouse MAO catalytic aclivities (15.59 $\mathrm{nmol} / \mathrm{mg} / 20 \mathrm{~min}$ for MAO A and $1.82 \mathrm{nmol} / \mathrm{mg} / 20 \mathrm{~min}$ for MAO B) suggests that mouse MAO promoters are different from humans.

Alignment of the promoter sequences of human MAO A and $\mathrm{B}$ showed that the most active fragments in MAO A and $\mathrm{B}$ (A0.14 and B0.15) were located in the corresponding regions where the $5^{\prime}$ flanking sequences showed high sequence identity (Fig. 1). The downstream 90 bp repeat in MAO A, which is needed for the maximal MAO A promoter activity, shows marked sequence homology ( $57 \%$ identity) with the MAO B region containing sites $2-8$, the region where $\mathrm{MAO} B$ promoter activity resides.

\section{Discussion}

This report has shown that maximal promoter activity for MAO $A$ and $B$ is located in a $0.14 \mathrm{~kb}$ PvuII/DraII fragment and a $0.15 \mathrm{~kb}$ PstI/NaeI fragment, respectively. These fragments share approximately $60 \%$ sequence identity, are both GC-rich and contain multiple Sp1 binding sites, and are located at similar positions relative to the cDNA start sites ( 3 bp downstream and 21 bp upstream of the cDNA start site for MAO A and B, respectively). These results suggest that the two promoters may be derived from the same ancestral gene, possibly by gene duplication process (Grimsby et al., 1991). However, the transcription factor binding sequences are not conserved; none of them were located at the corresponding positions of the two promoters. MAO B promoter has a TATA box and a CACCC element in its core region, but the corresponding part of the MAO A promoter lacks such elements. The Spl sites in the core region of the two promoters are in opposite orientations. These differences will certainly affect the way in which these two genes are regulated and provide mechanisms underlying their tissueand cell-specific expression.

Our results clearly demonstrate that MAO A promoter activity resides in the two 90 bp repeat region, which can actively initiate transcription in the absence of a TATA box. This result is in agreement with the multiple transcription initiation sites detected in this region for SHSY -5Y and HEL cells. It is also consistent with the human liver MAO A cDNA start site, which is $7 \mathrm{bp}$ downstream of the two repeats. On the other hand, the fact that the most upstream initiation site detected in SHSY$5 \mathrm{Y}$ and HEL cells is near the $5^{\prime}$ end of the upstream repeat and 34 bp $3^{\prime}$ of the TAATAA sequence suggests possible existence of a TATA-dependent MAO promoter activity upstream. However, the activity of the sequences $5^{\prime}$ of the TAATAA sequence (in the A0.21 RsaI/RsaI fragment) could be detected only occasionally, and the measured activity was low (less than $2 \%$ ). Thus, unlike the two 90 bp repeats, which persistently exhibited promoter activity in all measurements, the TATA-dependent promoter activity, if it exists, seems to be very sensitive to experimental conditions. It is possible that we have not found the optimal conditions for this activity. The A0.21 RsaI/RsaI fragment contains the TAATAA sequence (site 5), a CCAAT box (site 8), some CCAAT-like sequences (like GTTCAATA at -334 and CCAGTA at -312), and two CACCC elements (sites 6 and 7, Figs. 1, 2). If this is a functional promoter, then the MAO A gene would be controlled by two promoter regions: one is the classical CCAAT-TATA type promoter, represented by the A0.21 RsaI/RsaI fragment; the other is of housekeeping type, $\mathrm{GC}$-rich and composed of $\mathrm{Spl}$ binding sites, represented by the 
two 90 bp repeats. At present, it is not clear how these two promoter regions work under physiological conditions for the endogenous MAO A gene. Under our experiment conditions, the CCAAT-TATA region strongly downregulated the activity of the two $90 \mathrm{bp}$ repeats, but the effect of the two repeats on the TATA-dependent activity is currently unclear.

For MAO B, the highest promoter activity is provided by the Sp1-CACCC-Sp1-TATA structure contained in the B0.15 PstI/ NaeI fragment. Careful inspection of the Spl binding sites ( 3 , 4,5 , and 7,8 ) in this fragment (Fig. 1) leads to an interesting hypothesis. The $5^{\prime} \mathrm{Spl}$ binding region contains two overlapping Spl binding sites (sites 7,8 ) as underlined:

\section{GGGCGGGGGCGG T GG}

The distance between the "central C" of the two sites is $6 \mathrm{bp}$. Since each complete turn of B-DNA takes 10.4 bp (Wang, 1979), these two sites are located at opposite sides of the DNA molecule. However, only one $\mathrm{Sp} 1$ molecule can bind to this region, since for two $\mathrm{Spl}$ molecules to bind side by side, the shortest distance between the "central C" of the two Spl binding sites should at least be 10 bp (Gidoni et al., 1985). Similarly, at the $3^{\prime} \mathrm{Sp} 1$ binding region (sites $3-5$ ) a $\mathrm{Sp} 1$ molecule could bind to three different positions as underlined:

\section{T A AGCGGGCGGGCGGGG}

But still, only one $\mathrm{Sp} 1$ can bind to this region at any given time. This overlapping $\mathrm{Sp} 1$ binding structure may provide the MAO $B$ promoter with additional ways for the fine tuning of transcription regulation. For instance, at different $\mathrm{Spl}$ concentrations, $\mathrm{Sp} 1$ molecules may preferentially bind to certain positions due to different affinities of these overlapping $\mathrm{Spl}$ sites. This in turn will change the relative positions of the two bound Spl molecules with respect to the TATA box and the CACCC element in the Sp1-CACCC-Sp 1-TATA structure, thus altering the interaction between these factors.

Both promoters contain additional potential $\mathrm{Sp} 1$ binding sites, CACCC elements, CCAAT boxes, and direct repeats in the sequences upstream of their core regions. However, inclusion of these sequences (also the downstream $\mathrm{Spl}$ site 1 in MAO B promoter; Fig. 3) resulted in decreased promoter activity for both genes. Spl sites, CACCC elements, and CCAAT boxes are generally considered positive elements for transcription activation. Our results suggest that they could act as downregulating elements as well. These results are similar to the observation with the Abelson (ABL) gene promoter (Q.-S. Zhu, unpublished observations), in which the activity of an $\mathrm{Sp1-Sp1} \mathrm{structure} \mathrm{is}$ downregulated by additional transcription factor binding sites, either upstream or downstream. The downregulation may result from competition of these binding sites for transcription factors. This transcription factor binding will in turn compete for the activating domain on the polymerase complex.

Our results show that the A0.14 or B0.15 fragment exhibited very different promoter activities in different cell lines (SHSY$5 \mathrm{Y}>\mathrm{COS} 7>$ NIH3T3 for MAO A, Fig. 2; NIH3T3 > SHSY$5 \mathrm{Y}>\mathrm{COS} 7$ for MAO B, Fig. 3). However, the relative promoter activities of various fragments in these three cell lines are similar
(Figs. 2, 3). These results suggest that these fragments may not contain tissue specific elements. The different activities of the same fragments observed in various cell lines may be caused by different (trans) factors (either positive or negative) interacting with these fragments. The concentration or the modification (such as phosphorylation) of these transcription factors could be different in these cell lines. It has been shown that Spl concentration is a limiting factor for transcription in cultured mammalian cells (Saffer et al., 1990). Low concentration of Spl in certain cells would lead to low expression of genes containing its binding sites. In addition, differences in the concentration of negative factors in different cells may also contribute to the observed promoter activity differences. For example, both A0.14 and B0.15 fragments contain a consensus binding sequence (GCGGGGC) for the sequence-specific transcription repressor GC factor (GCF; Kageyama and Pastan, 1989). This GCF binding site overlaps with site 2 in MAO A promoter and site 3 in MAO B promoter and is likely to be involved in regulating expression of both MAO genes. Variation of its concentration from one cell line to another might directly affect transcription efficiency.

The different tissue- and cell-specific distribution of MAO A and $\mathrm{B}$ may be explained by their different promoter organizations. In other words, the controlling mechanism for different expression of these two enzymes is most likely at the transcription level, as evidenced by the correlation between the mRNA level of MAO A and B and the corresponding catalytic activities (Grimsby et al., 1990). The differences in cis-elements and their organizations found in MAO A and B promoters suggest that the observed differential expression of the MAO A and B constructs could be due to the different extent to which the requirement of MAO A and B promoters are satisfied by the existing transcription factors in the given cells. For example, certain CACCC binding factors are needed for high-level expression of MAO B, but the core part of the MAO A promoter does not have such a requirement. Low level of $\mathrm{CACCC}$ binding factor in a given cell may affect MAO B expression, but may less likely affect MAO A. Although both MAO A and B promoter seem to use $\mathrm{Spl}$ as their essential transcription factor, the optimal concentration of cellular $\mathrm{Sp} 1$ for MAO A and B might be rather different. It is also likely that these two promoters contain binding sites for unidentified transcription factors, and the type and location of these sites are different in the two promoters. In addition, these two promoters are different also in their sequences responsive to external hormonal stimulation from local environments. For example, AP- 1 binding site is found in $\mathrm{MAO}$ B promoter (site 19, Fig. 3, Table 1) but not in MAO A promoter. Both promoters contain cAMP response element-like sequence, but their locations are different (site 12 at -618 in MAO A and sitc 18 at -807 in MAO B; Figs. 2, 3; Table 1). Thus, MAO A and $B$ genes may respond differently to the environments of the cells within which they are located.

Abnormal levels of MAO activity have been reported in a number of mental disorders, such as depression (White et al., 1980), alcoholism (Sullivan et al., 1979), schizophrenia (Wyatt and Murphy, 1976), and Alzheimer's disease (Oreland et al., 1984). The abnormal MAO catalytic activity and biochemical characteristics have been observed in the second generation of the alcoholized rats (Anokhina et al., 1990), suggesting that MAO gene structure may be modified. Differences in human MAO A promoter sequences have been observed. For example, four potential Spl binding sites (sites 1-4) are found in the two 
90 bp repeats in our MAO A clone (Figs. 1, 2), whereas in the corresponding region of another human $\mathrm{MAO} A$ gene reported (Chen et al., 1991), two Sp1 sites (sites 1 and 3) are missing. If these differences are not due to sequencing errors, they would suggest heterogeneity of MAO promoter. Further, since these variations are located at important cis-elements, they may affect the expression of MAO A gene. It will be interesting to investigate whether the varied MAO levels in disease states are caused by promoter modification (cis-element changes), or by changes of transcription factors required for MAO expression. This work opens up a new area of research concerning the molecular basis of MAO gene expression in disease states.

\section{References}

Anokhina IP, Ovchinnikova LN, Khristolyubova NA, Gorkin VZ (1990) Evidence for impairment of liver monoamine oxidase properties in offspring of alcoholized rats. Biog Amines 7:95-105.

Bach AWJ, Lan NC, Johnson DL, Abell CW, Bembenek ME, Kwan S-W, Sccbcrg PH, Shih JC (1988) cDN $\Lambda$ cloning of human monoamine oxidase $A$ and $B$ : molecular basis of differences in enzymatic properties. Proc Natl Acad Sci USA 85:4934-4938.

Bond PA, Cundall RL (1977) Properties of monoamine oxidase (MAO) in human blood platelets, plasma, lymphocytes and granulocytes. Clin Chim Acta 80:317-326.

Breathnach R, Chambon P (1981) Organization and expression of eucharistic split genes coding for proteins. Annu Rev Biochem 50: 349-383.

Chen C, Okayama H (1987) High-efficiency transformation of mammalian cells by plasmid DNA. Mol Cell Biol 7:2745-2752.

Chen S, Shih JC, Xu QP (1984) Interaction of $N$-(2-nitro-4-azidophenyl)-serotonin with two types of monoamine oxidase in rat brain. J Neurochem 43:1680-1687.

Chen ZY, Gokham SK, Huang JK, Wen L, Ezzeddine D, Aydin-Muderrisoglu N, Powell JF, Huang RH, Breakefield XO, Craig I, Hsu Y-PP (1991) Structure of the human gene for monoamine oxidase type A. Nucleic Acids Res 19:4537-4541.

Chiba K, Trevor A, Castagnoli N (1984) Metabolism of the neurotoxic tertiary amine, MPTP by brain monoamine oxidase. Biochem Biophys Res Commun 120:574-578.

Curran T, Franza BR Jr (1988) Fos and Jun: the AP-1 connection. Cell 55:395-397.

Donnelly CH, Murphy DL (1977) Substrate- and inhibitor-related characteristics of human platelet monoamine oxidase. Biochem Pharmacol 26:853-858.

Dynan W, Sazer S, Tjian R, Schimke T (1986) Transcription factor $\mathrm{Sp} 1$ recognizes a DNA sequence in the mouse dihydrofolate reductase promoter. Nature 319:246-248.

Egashira T, Yamanaka Y (1981) Further studies on the synthesis of A-form of MAO. Jpn J Pharmacol 31:763-770.

Fowler JB, Macgregor RR, Wolf AP, Arnett CD, Dewey SL, Schlyer D, Christman D, Logan J, Smith M, Sachs H, Aquilonius SM, Bjurling $P$, Halldin C, Hartvig P, Leenders KL, Lundqvist $H$, Oreland $L$, Stålnacke C-G, Långström B (1987) Mapping human brain monoamine oxidase $A$ and $B$ with "C-labelled suicide inactivators and PET. Science 235:481-485.

Fritz RR, Abell CW, Patel NT, Gessner W, Brossi A (1985) Metabolism of the neurotoxin in MPTP by human liver monoamine oxidase B. FEBS Lett 186:224-228.

Garrick NA, Murphy DL (1982) Monoamine oxidase type A: differences in selectivity towards norepinephrine compared to serotonin. Biochem Pharmcol 31:4061-4066.

Gidoni D, Kadonaka JT, Barrera-Saldana H, Takahashi K, Chambon $P$, Tjian R (1985) Bidirectional SV40 transcription mediated by tandem Spl binding interactions. Science 230:511-517.

Greenawalt JW, Schnaitman C (1970) An appraisal of the use of monoamine oxidase as an enzyme marker for the outer mitochondrial membrane. J Cell Biol 46:173-179.

Grimsby J, Lan NC, Neve R, Chen K, Shih JC (1990) Tissue distribution of human monoamine oxidase $A$ and $B$ mRNA. J Neurochem 55:1166-1169.
Grimsby J, Chen K, Wang LJ, Lan NC, Shih JC (1991) Human monoamine oxidase $A$ and $B$ genes exhibit identical exon-intron organization. Proc Natl Acad Sci USA 88:3637-3641.

Gumucio DL, Rood KL, Gray TA, Riordan MF, Sartor CI, Collins FS (1988) Nuclear proteins that bind the human gamma-globin gene promoter: alterations in binding produced by point mutations associated with hereditary persistence of fetal hemoglobin. Mol Cell Biol 8:5310-5322.

Hsu Y-P, Weyler W, Chen S, Sims KB, Rinehart WB, Utterback M, Powell JF, Breakefield XO (1988) Structural features of human monoamine oxidase A elucidated from $\mathrm{CDNA}$ and peptide sequences. J Neurochem 51:1321-1324.

Ito A, Kuwahara T, Inadoma S, Sagara Y (1988) Molecular cloning of a cDNA for rat liver monoamine oxidase B. Biochem Biophys Res Commun 157:970-976.

Johnston JP (1968) Some observations upon a new inhibitor of monoamine oxidase in brain tissue. Biochem Pharmacol 17:1285-1297.

Kageyama R, Pastan I (1989) Molecular cloning and characterization of a human DNA binding factor that represses transcription. Cell 59: 815-825.

Knoll J, Magyar K (1972) Some puzzling pharmacological effects of monoamine oxidase inhibitors. In: Advances in biochemical psychopharmacology, Vol 5, Monoamine oxidases-new vista (Costa E, Sandler M, eds), pp 393-408. New York: Raven.

Kuwahara T, Takamoto S, Ito A (1990) Primary structure of rat monoamine oxidase $A$ deduced from $\mathrm{CDNA}$ and its expression in rat tissues. Agric Biol Chem 54:253-257.

Lan NC, Heinzmann C, Gal A, Klisak I, Orth U, Lai E, Grimsby J, Sparkes RS, Mohandas T, Shih JC (1989) Human monoamine oxidase $A$ and $B$ genes map to $\mathrm{Xp1} 1.23$ and are deleted in a patient with Norrie disease. Genomics 4:552-559.

Levitt P, Pintar JE, Breakefield XO (1982) Immunocytochemical demonstration of monoamine oxidase $B$ in brain astrocytes and serotonergic neurons. Proc Natl Acad Sci USA 79:6385-6389.

Lewinsohn R, Glover W, Sandler M (1980) Development of benzylamine oxidase and monoamine oxidase $A$ and $B$ in man. Biochem Pharmacol 29:1221-1230.

Means AL, Farnham PJ (1990) Transcription from the dihydrofolate reductase promoter is positioned by HIP1 binding at the initiation site. Mol Cell Biol 10:653-661.

Montminy MR, Sevarino KA, Wagner JA, Mandel G, Goodman RH (1986) Identification of a cyclic-AMP-responsive element within the rat somatostatin gene. Proc Natl Acad Sci USA 83:6682-6686.

Oreland L, Arai Y, Stenstrom A (1984) Age, neuropsychiatric diseases and brain monoamine oxidase. In: Monoamine oxidase and disease (Tipton KF, Dostert P, Strolin-Benedetti M, eds), pp 291-295. London: Academic.

Ozelius L, Hsu Y-P-P, Bruns G, Powell JF, Chen S, Weyler W, Utterback M, Zucker D, Haines J, Trofalter JA, Conneally PM, Gusella JF, Breakefield XO (1988) Human monoamine oxidase gene (MAOA): chromosome position (Xp21-p11) and DNA polymorphism. Genomics 3:53-58.

Saffer JD, Jackson SJ, Thurston SJ (1990) SV40 stimulates expression of the trans-acting factor Spl at the mRNA level. Genes Dev 4:659666.

Sambrook J, Fritsch EF, Maniatis T (1989) Molecular cloning: a laboratory manual, 7.79-7.83. Cold Spring Harbor, NY: Cold Spring Harbor Laboratory.

Sanger F, Nicklen S, Coulson AR (1977) DNA sequencing with chainterminating inhibitors. Proc Natl Acad Sci USA 74:5463-5467.

Santoro C, Mermod N, Andrews PC, Tjian T (1988) A family of human CCAAT-box-binding proteins active in transcription and DNA replication: cloning and expression of multiple cDNAs. Nature 334: 218-224.

Schule R, Muller M, Otsuka-Murakami H, Renkawitz R (1988) Cooperativity of the glucocorticoid receptor and the CACCC-box binding factor. Nature 332:87-90.

Selden RF, Burke Howie K, Rowe ME, Goodman HM, Moore DD (1986) Human growth hormone as a reporter gene in regulation studies employing transient gene expression. Mol Cell Biol 6:31733179.

Shih JC (1991) Molecular basis of human MAO A and B. Neuropsychopharmacology 4:1-7.

Sims KB, de la Chapelle A, Norio R, Sankila E-M, Hsu Y-P-P, Rinehart WB, Corey TJ, Ozelius L, Powell JF, Bruns G, Gusella JG, Murphy 
DL, Breakefield XO (1989) Monoamine oxidase deficiency in males with an $X$ chromosome deletion. Neuron 2:1069-1076.

Smale ST, Schmidt MC, Berk AJ, Baltimore D (1990) Transcriptional activation by Spl as directed through TATA or initiator: specific requirement for mammalian transcription factor IID. Proc Natl Acad Sci USA 87:4509-4513.

Sullivan JL, Cavenar JO Jr, Maltbie AA, Lister P, Zung WWK (1979) Familial biochemical and clinical correlates of alcoholics with low platelet monoamine oxidase activity. Biol Psychiatry 14:385-394.

Thorpe LW, Westlund KN, Kochersperger LM, Abell CW, Denney RM (1987) Immunocytochemical localization of monoamine oxidase $A$ and $B$ in human peripheral tissues and brain. J Histochem Cytochem $35: 217-236$ von Korff RW (1979) Monoamine oxidase: unanswered questions. In: Monoamine oxidase: structure, function, and altered functions (Singer TP, von Korff RW, Murphy DL, eds), pp 1-7. New York: Academic. Wang JC (1979) Helical repeat of DNA in solution. Proc Natl Acad Sci USA 76:200-203.

Westlund KN, Denney RM, Kochersperger LM, Rose RM, Abell CW (1985) Distinct monoamine oxidase A and B in primate brain. Science 230:181-183.

White K, Shih JC, Fong TL, Young H, Gelfand R, Boyd J (1980) Elevated platelet monoamine oxidase activity in non-endogenous depressives. Am J Psychiatry 37:1258-1259.

Wyatt RJ, Murphy DL (1976) Low platelet monoamine oxidase activity and schizophrenia. Schizophr Bull 2:77-89. 